\title{
Preparation and Properties of SMT Environmental Protection and High Efficient Lead-free Solder Paste
}

\author{
Zhi-wei Wang, Xuan Li, Hong Chen
}

1Hubei Province Key Laboratory of Green Light Materials, Wuhan 430068, China. 2School of Materials and Chemical Engineering, Hubei University of Technology, Wuhan 430068, China

Keywords: Environmental protection, Flux, Lead-free solder paste

Abstract. The components of the flux are optimized and the environmental friendly flux with excellent comprehensive performance is prepared. Then the composition of the solder paste is optimized to prepare the SMT environmental protection and high efficient lead-free solder paste, and its performance is studied. The results show that the storage stability, printability, weldability and environmental protection of the SMT environmental protection and high efficient lead-free solder paste are good, and the reliability is high. The related technical indexes have reached or superior to the commercial solder paste, and have reached the commercial level initially.

\section{Introduction}

In 21 st Century, SMT is becoming more and more popular in the global electronics industry, and has become the mainstream technology of electronic product assembly [1]. Solder paste is the important pillar of surface assembly technology, which directly affects the quality of electronic surface assembly in the aspects of printability and weldability [2]. For a long time, too much attention was paid to the welding performance and comprehensive cost of the traditional solder paste, but ignore the environmental pollution caused by some components or processes such as lead and its compounds, halogens, cleaning agents and so on [3-6].

\section{Test}

Materials. The name and specifications of the main materials and equipment used for the solder paste development are shown in Table 1 [7].

Table 1 Main materials

\begin{tabular}{cc}
\hline Component name & Materials \& specifications \\
\hline Welding powder & SAC0307 alloy powder 4\#(particle size $20 \mu \mathrm{m} \sim 38 \mu \mathrm{m})$ \\
Film forming agent & KE-604 rosin、A rosin(CP) \\
Solvent & A solvent、 DGBE、B solvent(AP) \\
Thixotropic agent & ST500(AP) \\
Activator & A acid、B acid、C acid、TEOA(AP) \\
surface active agent & FT-900(AP) \\
Other additives & BTA、BHT(AP) \\
\hline
\end{tabular}

Optimization of flux composition. According to the relevant procedures of uniform design test, the level of each factor was selected in Table 2. 
Table 2 Factor level $(\mathrm{g})$

\begin{tabular}{ccccccc}
\hline Level & $\mathrm{X} 1$ & $\mathrm{X} 2$ & $\mathrm{X} 3$ & $\mathrm{X} 4$ & $\mathrm{X} 5$ & $\mathrm{X} 6$ \\
\hline 1 & 42.5 & 37.5 & 4.5 & 7.5 & 0.75 & 0.75 \\
2 & 43 & 38 & 4.6 & 7.6 & 0.8 & 0.8 \\
3 & 43.5 & 38.5 & 4.7 & 7.7 & 0.85 & 0.85 \\
4 & 44 & 39 & 4.8 & 7.8 & 0.9 & 0.9 \\
5 & 44.5 & 39.5 & 4.9 & 7.9 & 0.95 & 0.95 \\
6 & 45 & 40 & 5 & 8 & 1 & 1 \\
7 & 45.5 & 40.5 & 5.1 & 8.1 & 1.05 & 1.05 \\
8 & 46 & 41 & 5.2 & 8.2 & 1.1 & 1.1 \\
9 & 46.5 & 42.5 & 5.3 & 8.3 & 1.15 & 1.15 \\
10 & 47 & 43 & 5.4 & 8.4 & 1.2 & 1.2 \\
11 & 47.5 & 43.5 & 5.5 & 8.5 & 1.25 & 1.25 \\
\hline
\end{tabular}

Optimization of solder paste composition. 9 solder paste samples were prepared by mixing SAC0307 (4\#) welding powder and environmental welders as shown in Table 3.

Table 3 Composition and proportion of solder paste sample

\begin{tabular}{cccccccccc}
\hline No. & $1 \#$ & $2 \#$ & $3 \#$ & $4 \#$ & $5 \#$ & $6 \#$ & $7 \#$ & $8 \#$ & $9 \#$ \\
\hline Welding powder & 87.0 & 87.5 & 88.0 & 88.5 & 89.0 & 89.5 & 90.0 & 90.5 & 91.0 \\
Flux & 13.0 & 12.5 & 12.0 & 11.5 & 11.0 & 10.5 & 10.0 & 9.5 & 9.0 \\
\hline
\end{tabular}

Reflow welding temperature curve. As shown in Fig.1, the preheating temperature range is 25 to $150^{\circ} \mathrm{C}$, the preheating time is $100 \mathrm{~s}$; the heat preservation temperature range is 150 to $190^{\circ} \mathrm{C}$, the heat preservation time is $75 \mathrm{~s}$; the reflow temperature range is 227 to $260^{\circ} \mathrm{C}$, the reflow time is $50 \mathrm{~s}$; the cooling temperature range is 227 to $25^{\circ} \mathrm{C}$, the cooling time is $101 \mathrm{~s}$; the peak temperature of the reflow welding curve is $260^{\circ} \mathrm{C}$.



Fig.1 Reflow welding temperature curve

Performance test of solder paste. According to IPC-TM-650 [8], IPC ANSI/J-STD-005A-2012 and other relevant standards, the storage stability, storage stability, printing, weldability, environmental protection, reliability and reliability of the environmentally friendly lead-free solder paste (HG0307) are tested, and the performance of the same type of commercial solder paste (SP0307) with better quality in the market is compared.

\section{Results and Analysis}

Optimum formula of flux. According to the factors and levels of Table 2, the uniform design table $\mathrm{U}_{11}\left(11^{6}\right)$ is adopted, and the test plan and result are shown in Table 4. 
Table 4 Test plan and results

\begin{tabular}{cccccccccccc}
\hline No. & 1 & 2 & 3 & 4 & 5 & 6 & 7 & 8 & 9 & 10 & 11 \\
\hline Y/\% & 85.12 & 87.85 & 84.26 & 79.59 & 78.33 & 88.37 & 82.56 & 87.63 & 79.27 & 82.51 & 85.57 \\
\hline
\end{tabular}

According to Table 4, there are 3 kinds of flux components with a spreading rate of more than $87 \%$, and the serial numbers are 2, 6 and 8 respectively. With the spreading rate greater than $87 \%$ and the lowest cost, the content of the No. 2 test plan is the best content of each component of environmental flux. The content of film forming agent, solvent, thixotropic agent, activator, surfactant and other additives in environmental flux is $44.1 \mathrm{wt} . \%, 40 \mathrm{wt} . \%, 5.2 \mathrm{wt} . \%, 8.6 \mathrm{wt} . \%, 0.9 \mathrm{wt} . \% .1 .2 \mathrm{wt} . \%$.

Optimum proportion of solder paste. Influence of welding powder content on the printing performance of solder paste.



Fig.2 Printing effect statistics of solder paste made from different contents of solder powder (A.Overprint;

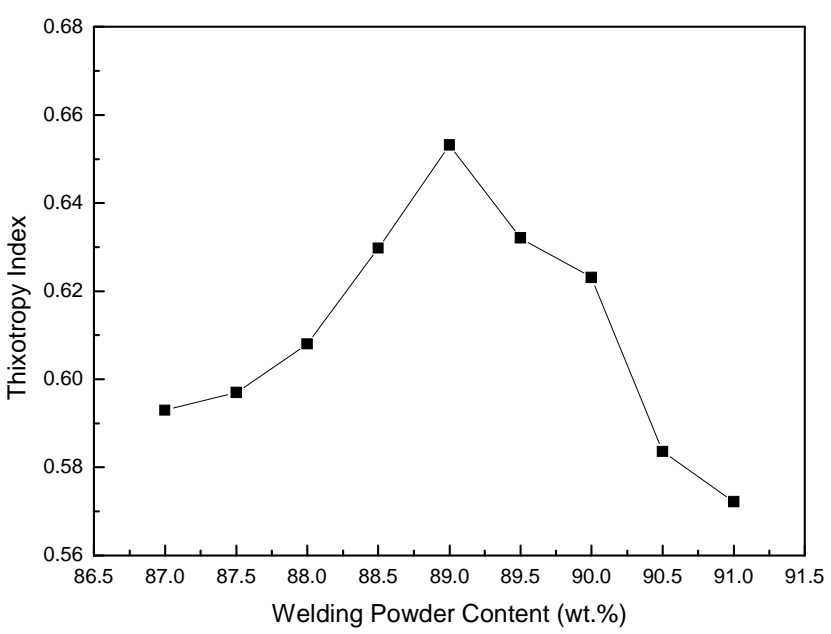

Fig.3 Influence of welding powder content on thixotropy index of solder paste

B.Suitable printing quantity; C.Too little printing)

As shown in Fig.2, with the increase of the content of the alloy powder, the proportion of B increased first and then decreased, the proportion of A gradually decreased, and the proportion of $\mathrm{C}$ gradually increased. The printing effect of the $5 \#$ sample ( $89 \mathrm{wt} . \%)$ was the best.

Influence of welding powder content on thixotropy of solder paste.

As shown in Fig.3, with the increase of the alloy powder content, the thixotropy index of solder paste increased first and then decreased. When the alloy powder content was $89 \mathrm{wt} . \%$, the thixotropy index of the solder paste was the largest, indicating that printing performance of the solder paste was better.To sum up, the ratio of 89:11 of 5\# sample is selected as the best ratio of SAC0307 (4\#) solder alloy powder and environmental flux.

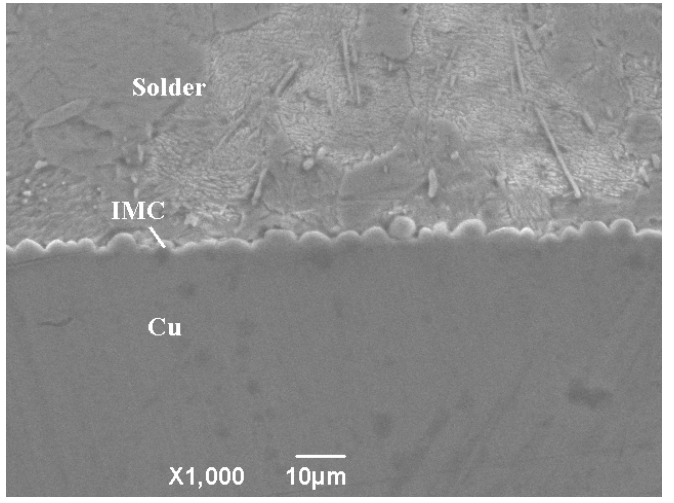

(a)Self-made HG0307 solder paste

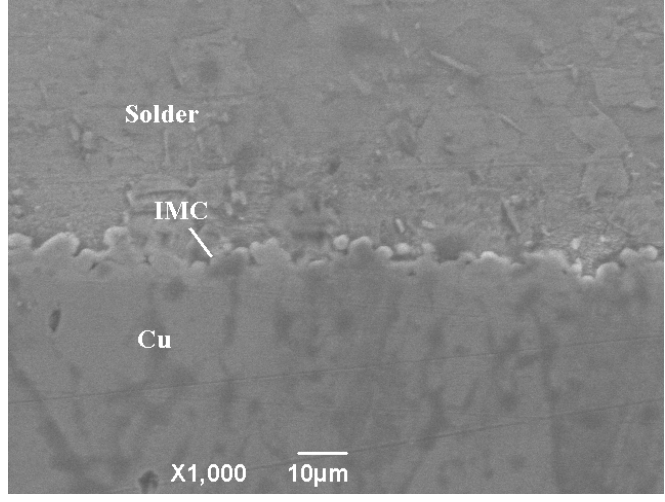

(b)Commodity SP0307 solder paste

Fig.4 SEM diagram of solder paste welding interface 
Comparison of microstructure of solder paste welding interface. As shown in Figure 4 (a) and (b), the solder interface of the two solder paste was followed by solder layer, IMC layer and Cu matrix layer.The IMC layer had a continuous scallop like distribution between the solder layer and the $\mathrm{Cu}$ matrix, and there is no obvious micro crack and other welding defects. It showed that the solder and the $\mathrm{Cu}$ matrix have formed a complete and effective metallurgical connection. The average IMC thickness of the welding interface between commercial SP0307 solder paste and self-made HG0307 solder paste was $3.6 \mathrm{mu} \mathrm{m}$ and $2.7 \mathrm{mu}$ m respectively. The contrast showed that the IMC layer of the HG0307 solder paste interface was thinner and smooth, and the welding quality was better than that of the SP0307 solder paste.

Comparison of comprehensive technical indexes of solder paste. According to Table 5, it is known that SMT environmental protection and high efficiency lead-free HG0307 solder paste has good comprehensive performance. It meets the relevant technical requirements.

Table 5 Comparison of comprehensive technical indexes of solder paste

\begin{tabular}{|c|c|c|c|}
\hline Technical indicators & Technical requirement & HG0307 solder paste & SP0307 solder paste \\
\hline Storage stability & - & 10 months & 8 months \\
\hline Printing effect & Graphic integrity & Good & Preferable \\
\hline Spreading rate & $\geqq 75 \%$ & $87.61 \%$ & $85.63 \%$ \\
\hline Solder ball & No level 1, less than 3 level 2 & Level 1 & Level 2 \\
\hline Welding effect & - & Good & Good \\
\hline Residual corrosivity & - & No obvious corrosion & Less \\
\hline insulation resistance & $\geqq 1.0 \times 1011 \Omega$ & $8.5 \times 1013 \Omega$ & $7.9 \times 1013 \Omega$ \\
\hline Welding strength & $\longrightarrow$ & Higher & Higher \\
\hline Halogen content & - & No & Little \\
\hline RoHS prohibited & - & Least, within the limit & Less, within the limit \\
\hline
\end{tabular}

\section{Conclusion}

The best formula for environmental flux is film forming agent $44.1 \mathrm{wt} . \%$, solvent $40 \mathrm{wt} \%$, thixotropic agent $5.2 \mathrm{wt} . \%$, activator $8.6 \mathrm{wt} . \%$, surfactant $0.9 \mathrm{wt} . \%$, and other additives $1.2 \mathrm{wt} \%$. SMT environmental protection and high efficiency lead-free solder paste is composed of 4\#SAC0307 solder alloy powder and environmentally friendly flux according to the best mass ratio of 89:11. The storage stability, printability, weldability and environmental protection of the SMT environmental protection and high efficient lead-free solder paste are good, and the reliability is high. According to the RoHS environmental instruction and related technical requirements, the related technical indexes have reached or superior to the commercial SP0307 solder paste, and have reached the commercial level initially.

\section{References}

[1] Wen-dian Zhang. Practical surface assembly technology [M].Beijing: Electronic Industry Press,2015.

[2] Zhong-zhong Jia. Analysis and case analysis of SMT core process [M].Beijing: Electronic Industry Press,2016.

[3] G.S. Gan,C.H. Du,etc. Design of lead-free solders and pollution control of lead[J].Advanced Materials Research, 2014,881-883:1435-1438.

[4] CL Chung,LT Lu,YJ Lee.Influence of halogen-free compound and lead-free solder paste on on-board reliability of green chip scale package[J].Microelectronics Reliability,2005,45(12):1916-1923.

[5] Wack H, Becht J. Cleaning No-clean Solder and Flux[J].Surface mount technology, 2010,2(6): 62-65.

[6] Bastow E.The effect of reflow profiling on the electrical reliability of no-clean solder paste flux residues[C].Las Vegas,NV,United states: Association Connecting Electronics Industries,2014. 
[7] Xuan Li. Study on the preparation and properties of SMT environmental protection lead-free solder paste[D].Wuhan: Hubei University of Technology,2018.

[8] IPC-TM-650 Test Methods Manual[M].Solder Powder Particle Size Distribution-Optical Image Analyzer Method.USA:The Institute for Interconnecting and Packing Electronic Circuit,2005. 